\title{
Mechanism underlying the transient increase of serum iron during FOLFOX/FOLFIRI therapy
}

\author{
TAKUMI OCHIAI $^{1}$, KAZUHIKO NISHIMURA ${ }^{1}$, TOMOO WATANABE $^{1}$, MASAYUKI KITAJIMA ${ }^{1}$, \\ AKINORI NAKATANI $^{1}$, TSUYOSHI SATO ${ }^{1}$, KENJI KISHINE ${ }^{1}$, SHUNJI FUTAGAWA ${ }^{1}$, \\ SATOMI MASHIKO $^{2}$ and ISAO NAGAOKA ${ }^{3}$ \\ Departments of ${ }^{1}$ Surgery and ${ }^{2}$ Pharmacy, Tobu Chiiki Hospital, Tokyo Metropolitan Health and \\ Medical Treatment Corporation, Tokyo 125-8512; ${ }^{3}$ Department of Host Defense and Biochemical Research, \\ Juntendo University School of Medicine, Tokyo 113-8421, Japan
}

Received May 13, 2014; Accepted July 9, 2014

DOI: $10.3892 / \mathrm{mco} .2014 .385$

\begin{abstract}
In patients with advanced colorectal cancer (CRC), a transient significant increase of serum iron is observed during chemotherapy with leucovorin and fluorouracil plus oxaliplatin (FOLFOX) or leucovorin and fluorouracil plus irinotecan (FOLFIRI). Serum iron may be a useful and convenient predictor of the response to chemotherapy; however, the mechanism underlying its increase has not been fully elucidated. Accordingly, the mechanism underlying the elevation of serum iron during chemotherapy was investigated in 20 patients with advanced CRC who were treated between September, 2012 and July, 2013. The levels of iron, ferritin, aspartate aminotransferase (AST), alanine aminotransferase (ALT), hemoglobin (Hb), hepcidin-25, interleukin (IL)-6 and soluble transferrin receptor (sTfR) were measured before and $48 \mathrm{~h}$ after chemotherapy. The serum levels of iron and hepcidin-25 were found to be significantly increased after chemotherapy $(\mathrm{P}<0.0001)$, whereas those of IL-6 were significantly decreased $(\mathrm{P}=0.0057)$. There were no significant changes in any of the other parameters. The lack of significant changes in AST, ALT and Hb suggested that the elevation of serum iron was not due to the destruction of hepatocytes, whereas the stable sTfR level suggested no destruction of erythroblasts. Hepcidin-25 regulates iron metabolism and decreases serum iron levels; it is increased by an iron load and IL-6, but is decreased under anemic or hypoxic conditions. The suppression of erythropoiesis increases serum iron levels and chemotherapy suppresses erythropoiesis. As serum iron and hepcidin- 25 were both significantly increased and IL-6 was significantly decreased, with no significant changes in sTfR, it
\end{abstract}

Correspondence to: Dr Takumi Ochiai, Department of Surgery, Tobu Chiiki Hospital, Tokyo Metropolitan Health and Medical Treatment Corporation, 5-14-1 Kameari, Katsushika-ku, Tokyo 125-8512, Japan

E-mail: takumi-o@ma.kitanet.ne.jp

Key words: serum iron, hepcidin, interleukin-6, soluble transferrin receptor, chemotherapy appears that the elevation of serum iron during chemotherapy may be secondary to reduced iron consumption by erythropoiesis, leading to increased expression of hepcidin-25 and suppression of Il-6 via negative feedback.

\section{Introduction}

Serum iron levels have been reported to increase following administration of various anticancer drugs, including 5-fluorouracil, actinomycin $\mathrm{D}$, adriamycin and cyclophosphamide. We previously demonstrated that a transient significant increase of serum iron was a recurrent event during treatment with leucovorin and fluorouracil plus oxaliplatin (FOLFOX) or leucovorin and fluorouracil plus irinotecan (FOLFIRI) in patients with advanced colorectal cancer (CRC), while there was no such effect of molecular-targeted drugs on serum iron levels (1). We also observed that the median survival time (MST) of patients with a greater increase of serum iron was significantly superior to that of other patients, while the multivariate analysis identified a small increase of serum iron as an independent risk factor for overall survival (OS). Thus, serum iron levels may represent a useful and convenient predictor of the response to chemotherapy $(2,3)$.

However, the mechanism underlying the increase of serum iron during chemotherapy remains to be elucidated. Accordingly, this study was performed to investigate the mechanism underlying the increase of serum iron during chemotherapy through measurement of hepcidin-25 as a key regulator of iron metabolism, interleukin (IL)-6 as a stimulator of hepcidin-25 and soluble transferrin receptor (sTfR) as a marker of erythroblasts.

\section{Materials and methods}

Patients. A total of 20 patients with unresectable advanced or metastatic CRC were enrolled in this study between September, 2012 and July, 2013. Treatment was based on the Japanese Society for Cancer of the Colon and Rectum guidelines (4) and all the patients received chemotherapy with FOLFOX or FOLFIRI, with or without molecular-targeted drugs (bevacizumab, cetuximab or panitumumab). No patient 
Table I. Patient characteristics.

\begin{tabular}{lc}
\hline Variables & Values \\
\hline No. of patients & 20 \\
Age, years [mean, (range)] & $70.8(51-82)$ \\
Gender (male/female) & $14 / 6$ \\
Primary tumor site (colon/rectum) & $18 / 2$ \\
Histological type, adenocarcinoma & \\
Well-differentiated & 2 \\
Moderately differentiated & 14 \\
Poorly differentiated & 3 \\
Signet ring cell carcinoma & 1 \\
\hline
\end{tabular}

received radiotherapy. Informed consent for measurement of the serum iron levels was obtained from the patients and this study was approved by the Tobu Chiiki Hospital Institutional Review Board (12.09.10. no. 2).

Methods. The serum levels of iron, ferritin, hemoglobin ( $\mathrm{Hb})$, aspartate aminotransferase (AST), alanine aminotransferase (ALT), hepcidin-25, sTfR and several cytokines were measured prior to and $48 \mathrm{~h}$ after chemotherapy.

Measurement of hepcidin-25. The serum concentrations of hepcidin-25 were determined by liquid chromatography tandem mass spectrometry (5-7).

For calibration, synthetic hepcidin isoforms were spiked in fetal bovine serum at final concentrations of 1, 2, 5, 10, $20,50,100,200,500$ and $1000 \mathrm{ng} / \mathrm{ml}$. A $50-\mu 1$ aliquot of $4 \%$ trichloroacetic acid solution containing $200 \mathrm{ng} / \mathrm{ml}$ $\left[{ }^{13} \mathrm{C}_{18},{ }^{15} \mathrm{~N}_{3}\right]$-hepcidin-25 as the internal standard was added to an equal volume of serum or calibration standard, mixed vigorously and centrifuged. A 20- $\mu 1$ aliquot of the resulting supernatant was analyzed quantitatively by liquid chromatography tandem mass spectrometry using the API-5500 QTRAP system (Applied Biosystems, Foster City, CA, USA) equipped with Prominence chromatographic system (Shimadzu Corp., Kyoto, Japan). Analytical chromatography of human hepcidin-20, -22 and -25 was performed on a PLRP-S column $(5 \mu \mathrm{m}, 300 \AA$, $150 \mathrm{~mm}$ x $2.0 \mathrm{~mm}$ i.d.; Polymer Laboratories, Ltd., Shropshire, UK). Mobile phase A was $0.1 \%$ aqueous formic acid and mobile phase B was $0.1 \%$ formic acid in acetonitrile. At a flow rate of $0.5 \mathrm{ml} / \mathrm{min}$, mobile phase B was commenced at $20 \%$ from $0-2 \mathrm{~min}$, increased to $25 \%$ until $8 \mathrm{~min}$, increased to $90 \%$ until $10 \mathrm{~min}$ and returned to $20 \%$ until $12 \mathrm{~min}$. Instrument control and data processing were performed with Analyst ${ }^{\mathrm{TM}}$ software, version 1.5 (Applied Biosystems).

Measurement of sTfR. sTfR was determined by Quantikine IVD ELISA (R\&D Systems, Inc., Minneapolis, MN, USA).

Measurement of cytokines. The serum concentrations of IL-1, IL-2, IL-4, IL-5, IL-6, IL-7, IL-8, IL-10, IL-12(p70), IL-13, IL-17, granulocyte colony-stimulating factor (G-CSF), granulocyte/macrophage colony-stimulating factor (GM-CSF), interferon (INF) $\gamma$, monocyte chemotactic protein-1 (MCP-1),

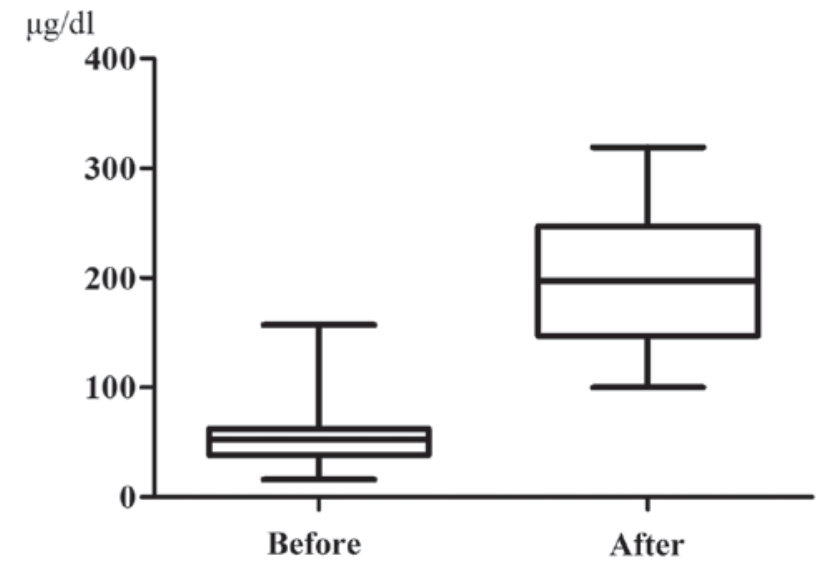

Figure 1. Serum iron level before and after chemotherapy $(\mathrm{P}<0.0001)$

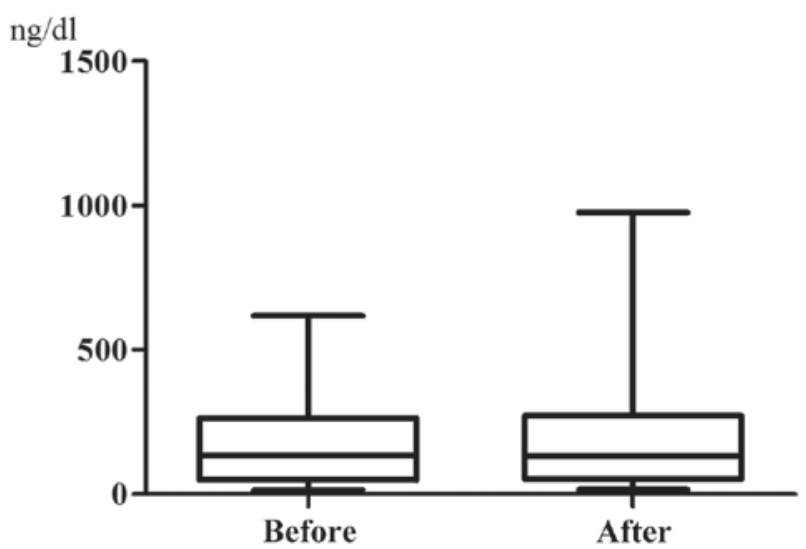

Figure 2. Ferritin level before and after chemotherapy $(\mathrm{P}=0.0974)$.

macrophage inflammatory protein-1 $\beta$ (MIP-1 $\beta$ ) and tumor necrosis factor $\alpha(\mathrm{TNF} \alpha)$ were measured by the multiplex method with a human 17-plex panel (Bio-Rad, Hercules, CA, USA), according to the manufacturer's instructions. The detection limit for each cytokine was $4 \mathrm{pg} / \mathrm{ml}$.

Statistical analysis. The t-test was used for comparisons between two groups and $\mathrm{P}<0.05$ was considered to indicate a statistically significant difference. Data are expressed as means \pm standard deviation.

\section{Results}

Patient characteristics. The characteristics of the patients are summarized in Table I. The 20 patients had a mean age of 70.8 years (range, 51-82 years) and included 14 men and 6 women. A total of 18 patients had colon cancer and 2 patients had rectal cancer.

Laboratory parameters before and after chemotherapy. The serum iron level was $56.95 \pm 32.70 \mu \mathrm{g} / \mathrm{dl}$ prior to chemotherapy and it increased significantly to $201.9 \pm 67.71 \mu \mathrm{g} / \mathrm{dl}$ at $48 \mathrm{~h}$ after chemotherapy $(\mathrm{P}<0.0001$, Fig. 1). By contrast, the serum ferritin level did not change significantly, being $167.6 \pm 155.6 \mathrm{ng} / \mathrm{dl}$ before chemotherapy and increasing to $202.6 \pm 229.0 \mathrm{ng} / \mathrm{dl}$ after chemotherapy ( $\mathrm{P}=0.0974$, Fig. 2$)$. The 


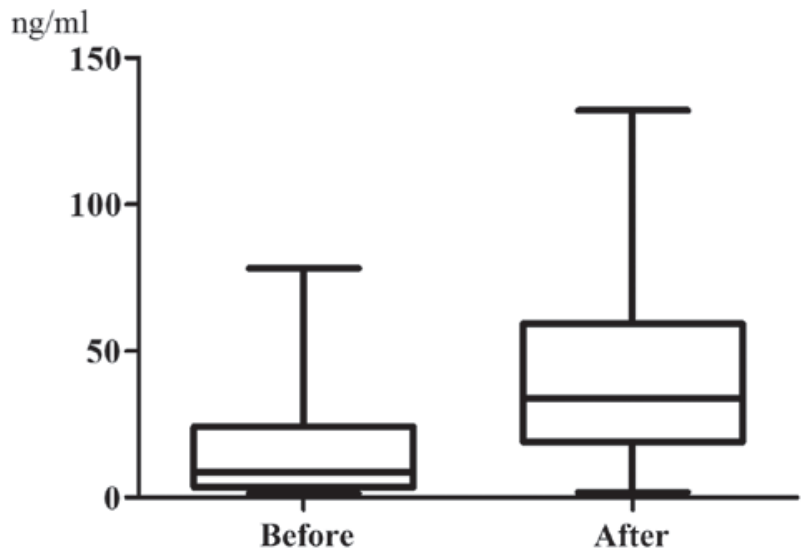

Figure 3. Serum hepcidin-25 level before and after chemotherapy $(\mathrm{P}<0.0001)$.

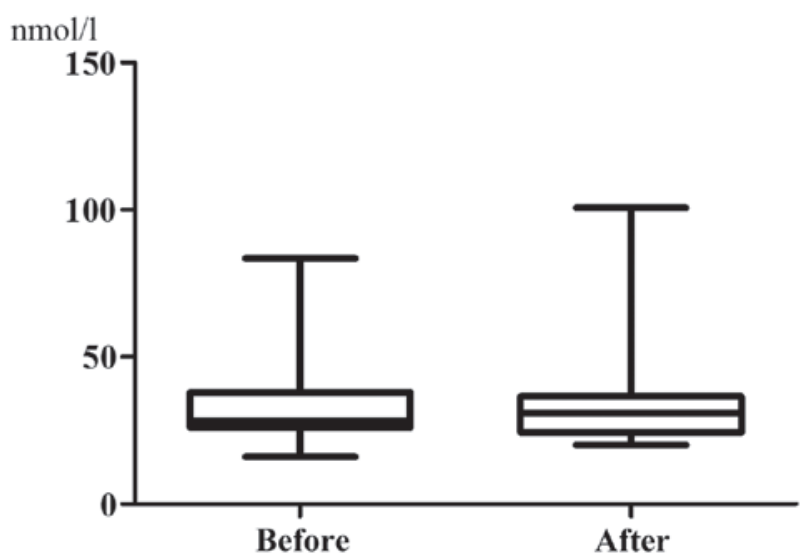

Figure 4. Soluble transferrin receptor level before and after chemotherapy $(\mathrm{P}=0.9133)$.

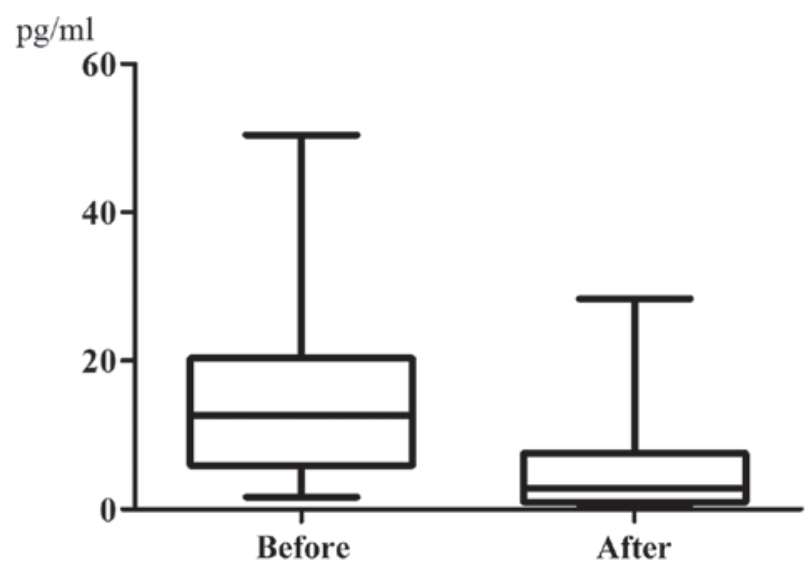

Figure 5. Interleukin-6 level before and after chemotherapy $(\mathrm{P}=0.0057)$.

serum hepcidin- 25 level was $15.29 \pm 18.17 \mathrm{ng} / \mathrm{ml}$ prior to chemotherapy and it increased significantly to $42.29 \pm 34.73 \mathrm{ng} / \mathrm{ml}$ at $48 \mathrm{~h}$ after chemotherapy $(\mathrm{P}<0.0001$, Fig. 3). However, there was almost no difference between the sTfR levels before chemotherapy $(35.63 \pm 18.05 \mathrm{nmol} / \mathrm{l})$ and those after chemotherapy $(35.40 \pm 18.39 \mathrm{nmol} / \mathrm{l})(\mathrm{P}=0.9133$, Fig. 4). The serum IL-6 level was $14.51 \pm 11.39 \mathrm{pg} / \mathrm{ml}$ prior to chemotherapy and it exhibited a significant decrease to $5.420 \pm 7.216 \mathrm{pg} / \mathrm{ml}$ following
Table II. Laboratory parameters before and $48 \mathrm{~h}$ after chemotherapy.

\begin{tabular}{|c|c|c|c|}
\hline Variables & Before & After & P-value \\
\hline $\mathrm{Hb}(\mathrm{g} / \mathrm{dl})$ & $11.85 \pm 1.438$ & $11.4 \pm 14.97$ & NS \\
\hline AST (IU/l) & $28.15 \pm 15.49$ & $30.65 \pm 14.56$ & NS \\
\hline ALT (IU/l) & $22.20 \pm 8.727$ & $24.45 \pm 9.833$ & NS \\
\hline $\mathrm{IL}^{-1}{ }^{\mathrm{a}}$ & $1.832 \pm 1.140$ & $1.765 \pm 1.107$ & NS \\
\hline $\mathrm{IL} 2^{\mathrm{a}}$ & $0.3670 \pm 0.9257$ & $1.428 \pm 5.671$ & NS \\
\hline $\mathrm{IL}-4^{\mathrm{a}}$ & $3.452 \pm 1.419$ & $3.447 \pm 1.310$ & NS \\
\hline $\mathrm{IL} 5^{\mathrm{a}}$ & $6.633 \pm 3.417$ & $5.615 \pm 2.476$ & NS \\
\hline $\mathrm{IL} 7^{\mathrm{a}}$ & $17.08 \pm 7.171$ & $16.01 \pm 8.012$ & NS \\
\hline IL- $8^{\mathrm{a}}$ & $54.89 \pm 25.17$ & $52.65 \pm 22.66$ & NS \\
\hline IL-10 & $6.201 \pm 6.335$ & $5.396 \pm 5.081$ & NS \\
\hline $\mathrm{IL}-12^{\mathrm{a}}$ & $18.83 \pm 20.93$ & $15.44 \pm 18.58$ & NS \\
\hline IL-13 & $7.911 \pm 3.344$ & $6.536 \pm 2.899$ & NS \\
\hline IL-17 ${ }^{\mathrm{a}}$ & $19.53 \pm 12.86$ & $15.41 \pm 12.90$ & NS \\
\hline G-CSF ${ }^{a}$ & $63.01 \pm 39.07$ & $61.53 \pm 28.57$ & NS \\
\hline GM-CSF ${ }^{a}$ & $9.619 \pm 20.84$ & $5.303 \pm 1.363$ & NS \\
\hline $\mathrm{INF} \gamma^{\mathrm{a}}$ & $220.3 \pm 99.13$ & $215.4 \pm 78.49$ & NS \\
\hline $\mathrm{MCP}-1^{\mathrm{a}}$ & $48.77 \pm 41.34$ & $34.05 \pm 34.64$ & NS \\
\hline MIP-1 $\beta^{\mathrm{a}}$ & $131.3 \pm 49.94$ & $135.1 \pm 45.96$ & NS \\
\hline $\mathrm{TNF} \alpha^{\mathrm{a}}$ & $35.68 \pm 24.49$ & $37.27 \pm 26.91$ & NS \\
\hline
\end{tabular}

a all cytokines were measured at $\mathrm{pg} / \mathrm{ml}$. Hb, hemoglobin; AST, aspartate aminotransferase; ALT, alanine aminotransferase; IL, interleukin; G-CSF, granulocyte colony-stimulating factor; GM-CSF, granulocyte/ macrophage colony-stimulating factor; INF $\gamma$, interferon $\gamma$; MCP-1, monocyte chemotactic protein-1; MIP-1 $\beta$, macrophage inflammatory protein-1 $\beta$; TNF $\alpha$, tumor necrosis factor $\alpha$; NS, not significant.

chemotherapy ( $\mathrm{P}=0.0057$, Fig. 5). The data on the other laboratory parameters [Hb, AST, ALT, IL-1, IL-2, IL-4, IL-5, IL-7, IL-8, IL-10, IL-12(p70), IL-13, IL-17, G-CSF, GM-CSF, INF $\gamma$, MCP-1, MIP-1 $\beta$ and TNF $\alpha$ ] are summarized in Table II. The comparison between the serum concentrations before and after chemotherapy revealed no significant changes in any of these parameters up to $48 \mathrm{~h}$ after chemotherapy.

\section{Discussion}

Iron is essential for all human cells and it plays an important role in numerous biological processes, including electron and oxygen transport and DNA synthesis $(8,9)$. However, excess iron poses a threat to cells and tissues due to its ability to catalyze the generation of various radicals (10). Therefore, serum iron levels are strictly regulated in humans (11). In general, the daily loss of iron through desquamation of epithelial cells from the intestine and the skin (1-2 mg) represents $<0.1 \%$ of the total iron stores (3-4 g) in adults. The iron that is lost must be replaced from dietary sources by absorption in the duodenum to maintain the iron balance. If iron intake is excessive and overload occurs, the daily loss of iron cannot increase substantially through physiological mechanisms. 
Most of the iron in the body is found in hemoglobin within erythrocytes, accounting for $\sim 2 \mathrm{~g}$ in total, while serum only contains 3-4 mg of iron bound to transferrin, an iron carrier that is the exclusive source of iron for erythropoiesis. The lifespan of human erythrocytes is $\sim 120$ days, hence the oldest fraction of erythrocytes is degraded by macrophages and their iron is returned to transferrin on a daily basis. This recycling process generates a daily load of 20-25 mg of iron, most of which is destined for erythrocyte production in the bone marrow, where $\sim 1 \mathrm{mg}$ of iron/h is consumed for erythropoiesis. Therefore, if the supply of iron from macrophages is stopped, the iron in the serum will be consumed after only 3-4 h. By contrast, if erythropoiesis is suppressed, the serum iron levels will increase. The turnover of serum iron is rapid. Approximately $1 \mathrm{~g}$ of iron is stored by hepatocytes and macrophages in the liver and red pulp macrophages in the spleen. Hepatocytes and macrophages store iron in the cytoplasm bound to ferritin, so that it may be readily mobilized under conditions of high iron demand.

Hepcidin is synthesized in the liver and is a key peptide hormone that regulates iron homeostasis in humans (12-14). There are three forms of hepcidin, hepcidin-20, -22 and -25 . Hepcidin-25 is the mature bioactive form; it is a 25 -amino acid peptide hormone that inhibits iron entry into the serum compartment from the three main sources (dietary absorption from the duodenum, release of recycled iron from macrophages and release of stored iron from hepatocytes) by binding to ferroportin, a cellular iron exporter and inducing its internalization (15). Therefore, a high circulating level of hepcidin-25 decreases serum iron levels.

The synthesis of hepcidin-25 is activated by an iron load, whereas it is suppressed by anemia, hypoxia and erythropoiesis $(16,17)$. Hepcidin-25 synthesis is also induced by inflammatory cytokines, such as IL-6, in response to infection and inflammation, thus suppressing iron utilization and absorption and resulting in the anemia associated with inflammation or chronic disease (18). Under normal conditions, however, an increase of the serum iron level upregulates hepcidin-25 expression, which is under feedback regulation by serum iron concentrations and by the erythropoietic requirement for iron.

In this study, the serum iron and hepcidin-25 levels were significantly increased after chemotherapy, whereas those of IL-6 were significantly decreased and there were no significant changes in AST, ALT, Hb and sTfR levels. The lack of significant changes in AST, ALT and Hb levels suggests that the increase of serum iron was not due to the destruction of hepatocytes or erythrocytes by chemotherapy. In addition, the sTfR level reflects the number of erythroblasts; hence, the lack of a significant change in STfR suggests that erythroblasts were not affected by chemotherapy. Vokurka et al (19) observed that an increase in hepcidin was associated with irradiation-induced suppression of erythropoiesis in mice. Continuing absorption of iron from the gut and its release from macrophages are highly undesirable when erythropoiesis is suppressed. In fact, an increase of hepcidin has been observed in patients with severe anemia due to suppression of hematopoiesis by irradiation; it appears that hemolysis and anemia only decrease hepcidin levels when erythropoiesis is functional. If erythropoiesis is arrested, even severe anemia does not lead to a decrease in hepcidin, which, on the contrary, is significantly increased. Suppression of erythropoiesis is observed in acute leukemia, erythropoietin-deficiency anemia, aplastic anemia, pure red cell aplasia and myelodysplastic syndrome. In these diseases, the serum iron levels are high, despite the presence of anemia. While attacking cancer cells, chemotherapy also suppresses bone marrow function. Thus, the increase in hepcidin associated with chemotherapy in this study may be similar to the increase of hepcidin that occurs in patients with irradiation-induced suppression of erythropoiesis.

We previously demonstrated that the MST of patients with a marked increase of the serum iron levels was significantly superior to that of patients with a small increase, whereas the multivariate analysis identified a small increase of serum iron as an independent risk factor for OS $(2,3)$. The present study suggested that an increase of serum iron results from the suppression of erythropoiesis by chemotherapy, which may also indicate suppression of tumor cell proliferation. Therefore, serum iron levels may be a useful and convenient predictor of the response to chemotherapy.

There were several limitations to this study. The mechanism by which chemotherapy suppresses erythropoietic consumption of iron within a very short time remains to be elucidated. Fluorouracil, oxaliplatin and irinotecan are cytotoxic chemotherapeutic agents. In a preliminary study conducted at our hospital, the serum iron levels were found to increase during chemotherapy with docetaxel for gastric cancer. In general, cytotoxic agents disturb cell division and it requires some time for antitumor activity to appear. However, the suppression of erythropoiesis appeared to be very rapid in this study. Accordingly, cytotoxic agents may directly suppress heme protein synthesis in erythroblasts, or there may be other mechanisms involved.

In conclusion, the increase of serum iron levels during FOLFOX/FOLFIRI therapy may be attributed to the suppression of erythropoiesis and, thus, the decrease in the consumption of iron. Therefore, serum iron levels increase rapidly, leading to an increase of hepcidin-25 which, in turn, leads to a decrease in IL-6 levels via negative feedback. Thus, the elevation of serum iron levels during chemotherapy may be attributed to reduced iron consumption due to the suppression of erythropoiesis.

\section{Acknowledgements}

The authors would like to thank Yasushi Shimonaka, Product Research Department, Chugai Pharmaceutical Co., Ltd., Kamakura, Japan, for his cooperation with the measurement of hepcidin.

\section{References}

1. Mashiko S, Nagaoka I, Kitajima M, et al: Evaluation of serum iron levels during FOLFOX4 and FOLFIRI therapies. Exp Ther Med 1: 507-511, 2010.

2. Ochiai T, Nishimura K, Watanabe T, et al: Serum iron levels as a new biomarker in chemotherapy with leucovorin and fluorouracil plus oxaliplatin or leucovorin and fluorouracil plus irinotecan, with or without molecularly-targeted drugs. Mol Clin Oncol 1: 805-810, 2013.

3. Ochiai T, Nishimura K, Watanabe T, et al: Serum iron levels potential biomarker in FOLFOX/FOLFIRI with or without molecularly targeted drug therapy. J Clin Oncol 31 (Suppl): abs. e14651, 2013. 
4. Watanabe T, Itabashi M, Shimada Y, et al: Cancer of the colon and rectum (JSCCR) guidelines 2010 for the treatment of colorectal cancer. Int J Clin Oncol 17: 1-29, 2012.

5. Murphy AT, Witcher DR, Luan P and Wroblewski VJ: Quantitation of hepcidin from human and mouse serum using liquid chromatography tandem mass spectrometry. Blood 110: 1048-1054, 2007.

6. Murao N, Ishigai M, Yasuno H, Shimonaka Y and Aso Y: Simple and sensitive quantification of bioactive peptides in biological matrices using liquid chromatography/selected reaction monitoring mass spectrometry coupled with trichloroacetic acid clean-up. Rapid Commun Mass Spectrom 21: 4033-4038, 2007.

7. Kanda J, Mizumoto C, Kawabata H, et al: Serum hepcidin level and erythropoietic activity after hematopoietic stem cell transplantation. Haematologica 93: 1550-1554, 2008.

8. Ponka P: Cellular iron metabolism. Kidney Int Suppl 69: S2-S11, 1999.

9. Aisen P, Enns C and Wessling-Resnick M: Chemistry and biology of eukaryotic iron metabolism. Int J Biochem Cell Biol 33: 940-959, 2001.

10. Papanikolaou G and Pantopoulos K: Iron metabolism and toxicity. Toxicol Appl Pharmacol 202: 199-211, 2005.

11. Knutson $\mathrm{M}$ and Wessling-Resnick M: Iron metabolism in the reticuloendothelial system. Crit Rev Biochem Mol Biol 38: 61-88, 2003.

12. Krause A, Neitz S, Magert HJ, et al: LEAP-1, a novel highly disulfide-bonded human peptide, exhibits antimicrobial activity. FEBS Lett 480: 147-150, 2000.
13. Park CH, Valore EV, Waring AJ, et al: Hepcidin, a urinary antimicrobial peptide synthesized in the liver. J Biol Chem 276 7806-7810, 2001

14. Kemna EH, Tjalsma H, Willems HL and Swinkels DW: Hepcidin: from discovery to differential diagnosis. Haematologica 93 90-97, 2008.

15. Jordan JB, Poppe L, Haniu M, et al: Hepcidin revisited, disulfide connectivity, dynamics, and structure. J Biol Chem 284 24155-24167, 2009

16. Pigeon C, Ilyin G, Courselaud B, et al: A new mouse liver-specific gene, encoding a protein homologous to human antimicrobial peptide hepcidin, is overexpressed during iron overload. J Biol Chem 276: 7811-7819, 2001.

17. Nicolas G, Chauvet C, Viatte L, et al: The gene encoding the iron regulatory peptide hepcidin is regulated by anemia, hypoxia, and inflammation. J Clin Invest 110: 1037-1044, 2002.

18. Nemeth E, Valore EV, Territo M, Schiller G, Lichtenstein A and Ganz T: Hepcidin, a putative mediator of anemia of inflammation, is a type II acute-phase protein. Blood 101: 2461-2463, 2003.

19. Vokurka M, Krijt J, Sulc K and Necas E: Hepcidin mRNA levels in mouse liver respond to inhibition of erythropoiesis. Physiol Res 55: 667-674, 2006. 